\section{References}

${ }^{1}$ Douglas JWB. Maternity in Great Britain. London: Oxford University Press, 1948.

2 Douglas JWB, Blomfield JM. Children under five. London: George Allen and Unwin, 1958.

${ }^{3}$ Spence J, Walton WS, Miller FJW, Court SDM. A thousand families in Newcastle-upon-Tyne. London: Oxford University Press, 1954.

4 Miller FJW, Court SDM, Walton WS, Knox EG. Growing up in Newcastleupon-Tyne. London: Oxford University Press, 1960.

5 Butler NR, Alberman ED. Perinatal problems. Edinburgh: Livingstone, 1969.

- Davie R, Butler N, Goldstein H. From birth to seven. London: Longman, 1972.

${ }^{7}$ Chamberlain R, Chamberlain G, Howlett B, Claireaux A. British births, 1970. London: Heinemann, 1975.

${ }^{8}$ Chamberlain RN, Simpson RN. The prevalence of illness in childhood. Tunbridge Wells: Pitman Medical, 1979.

- Baker RJ, Nelder JA. The GLIM system. Release 3. Generalised linear interactive modelling manual. Oxford, Numerical Algorithms Group, 1979.

10 Walter SD, Elwood JM. A test for seasonality of events with a variable population at risk. British fournal of Preventive and Social Medicine 1975 ;29:18-21.

11 Slatis HM, deCloux RJ. Seasonal variations in stillbirth frequencies. Hum Biol 1967;39:284-94.

12 Sandahl B. Seasonal birth pattern in Sweden in relation to birth order and maternal age. Acta Obstet Gynecol Scand 1978;57:393-6.

13 Janerich DT, Garfinkel J. Season of birth and birth order in relation to prenatal pathology. Am $\mathcal{F}$ Epidemiol 1970;92:351-6.

14 Record RG. Anencephalus in Scotland. British fournal of Preventive and Social Medicine 1961 ;15:93-105.
15 Theander G. Seasonal distribution of births of boys with anomalies of the urethra. Scand f Urol Nephrol 1970;4:1-5.

${ }^{16}$ Harlap S. Time-series analysis of the incidence of Down's syndrome in West Jerusalem. Am 7 Epidemiol $1974 ; 99: 210-7$.

17 Sandahl B. Seasonal incidence of cleft lip and palate in Sweden, 1965-1974. Scand F Plast Reconstr Surg 1978;11:39-43.

18 Sandahl B. Seasonal incidence of some congenital malformations of the central nervous system. Acta Paediatr Scand 1977;66:65-72.

19 Rutstein DD, Nickerson RJ, Heald FP. Seasonal incidence of patent ductus arteriosus and maternal rubella. Am $\mathcal{F} D$ is Child $1952 ; 84: 199-213$.

${ }^{20}$ Janerich DT, Jacobson HI. Seasonality in Down's syndrome. An endocrinological explanation. Lancet $1977 ; \mathrm{i}: 515-6$.

21 Elwood JM. Seasonal variation in anencephalus in Canada. British fournal of Preventive and Social Medicine 1975;29:22-6.

${ }^{22}$ McKeown T, Record RG. Seasonal incidence of congenital malformations of the central nervous system. Lancet $1951 ; \mathrm{i}: 192-6$.

23 Weatherall R. Recent seasonal patterns of infant mortality in England and Wales. In: OPCS. Studies on medical and population subjects. No 31 London: HMSO, 1976.

24 Anonymous. Seasonality of birth in schizophrenia. Lancet 1978;i:481-2.

25 Lloyd B, Pursall E, Emery JL. Hospital morbidity pattern in children under 1 year of age born in Sheffield, 1975-6. Arch Dis Child 1981 ;56: 36-9.

${ }^{26}$ Cave DR, Freedman LS. Seasonal variations in the clinical presentation of Crohn's disease and ulcerative colitis. Int F Epidemiol 1975;4:317-20.

27 Registrar General. Statistical review for 1967. Part III. London: HMSO 1969.

${ }^{28}$ Steedman J. Progress in secondary schools. Findings from the National Child Development Study. London: National Children's Bureau, 1980. 29 Wilby P. Were the school figures fiddled? Sunday Times 1980 Sept 21.

(Accepted 18 November 1981)

\title{
Raised respiratory rate in elderly patients: a valuable physical sign
}

\author{
J P MCFADDEN, R C PRICE, H D EASTWOOD, R S BRIGGS
}

\begin{abstract}
Measurements of respiratory rate in 82 long-stay patients aged 67-101 years yielded a normal range of 16-25 breaths a minute. In a prospective study of 60 consecutive acute admissions to a geriatric unit, 19 out of 21 patients diagnosed as lower respiratory tract infections had respiratory rates above the upper limit of normal on the day of diagnosis; the rise in respiratory rate preceded the clinical diagnosis. All eight patients who were diagnosed on admission as having a lower respiratory tract infection had a respiratory rate greater than 26, with a mean of 29.7 breaths a minute. Patients admitted for other conditions-for example, urinary tract infection -rarely had respiratory rates outside the normal range.

Accurate measurement of respiratory rate is a valuable diagnostic aid in elderly patients.
\end{abstract}

\section{Introduction}

Regular recording of respiratory rate is commonplace in hospital wards, yet it is doubtful that clinicians pay much attention to such observations, particularly as compared with those of

Department of Geriatric Medicine, Centre Block, Level E, Southampton General Hospital, Southampton SO9 4XY

J P MCFADDEN, medical student

R C PRICE, medical student

H D EASTWOOD, MB, FRCP, consultant

R S BRIGGS, MSC, MRCP, senior lecture temperature and pulse rate. Hence a survey of routine measurement of respiratory rate by nurses concluded that it was an expensive tribute to tradition, performed in a perfunctory manner, apt to be highly inaccurate, and of little clinical value. ${ }^{1}$ Lower respiratory tract infections are frequent ${ }^{2}$ (and often terminal $^{3}$ ) events in elderly patients, however, but their onset may be insidious and unaccompanied by a rise in temperature."

Respiratory rate has been suggested as a sensitive index of acute illness in the elderly, ${ }^{5}$ though this has not been evaluated objectively. We have studied prospectively the respiratory rate in two groups of elderly patients: firstly, patients in long-stay wards to assess the variability of the measurement and to define a normal range; and, secondly, patients admitted to acute geriatric wards to observe the effects of acute respiratory or other illness. Inpatients were studied, since we were interested in the effects of illness on a clinical sign in the sick elderly rather than the effects of "normal aging" on the respiratory function of a healthy population.

\section{Patients and methods}

We studied 142 patients. The first group comprised all 82 patients (mean age 83.5 years) in five long-stay wards; 67 were women (mean age 85.4 years, range $73-101$ ) and 15 men (mean age 76.8 years, range 67-88). Respiratory rate in each patient was recorded on several occasions over two to three weeks, at a mean interval of three days (range one to five days); the study of the group as a whole lasted for five weeks. The second group comprised 60 patients (mean age 83.0 years) admitted consecutively to two acute wards; 33 were women (mean age 84.4 years, range $69-94$ ) and 27 men (mean age 81.9 years, range 74-93). These patients were monitored daily, the total period studied being 25 days. 
Respiratory rate was measured over 30 seconds while ostensibly taking the pulse, so that patients were not aware that respiration was being recorded. All recordings were made by the same two observers between 10 am and $330 \mathrm{pm}$ when patients were awake, resting, and not within one hour of a meal.

Recordings were not available to clinicians responsible for the patients, nor to nursing staff. At the end of the study we used information from the hospital case notes to subdivide our second group into (a) those patients in whom a lower respiratory tract infection had been diagnosed by the responsible clinicians, $(b)$ those diagnosed as having a urinary tract infection (chosen as a common example of nonrespiratory infection), and (c) a control group comprising all other patients admitted, irrespective of diagnosis. No patient was excluded. The study was approved by the local ethical committee.

\section{Results}

From the 82 long-stay patients a series of means and variances of respiratory rate was obtained over the five weeks. From these we derived an overall mean, together with a standard deviation calculated as the square root of the overall mean of the variances. The norma range of respiratory rate in this group of elderly patients was thus defined as $16-25$ breaths/min (mean $12 \mathrm{SD}$ ). There was no sex difference. The individual means on each day varied little over the five weeks, ranging from 20 to 22 breaths $/ \mathrm{min}$.

The 60 acute admissions provided 27 controls; their overall mean respiratory rate during the 25 days studied was $20 \cdot 5$ SD $2 \cdot 3$ breaths/ min. The figure shows the day-to-day variation in mean respiratory rate compared with that of the 12 patients diagnosed as having urinary tract infections and 21 patients with lower respiratory tract infections. Respiratory rate is plotted on either side of the day of diagnosis of infection (day 0) or, in the case of the controls, on either side of an arbitrary day (the midpoint of the study).

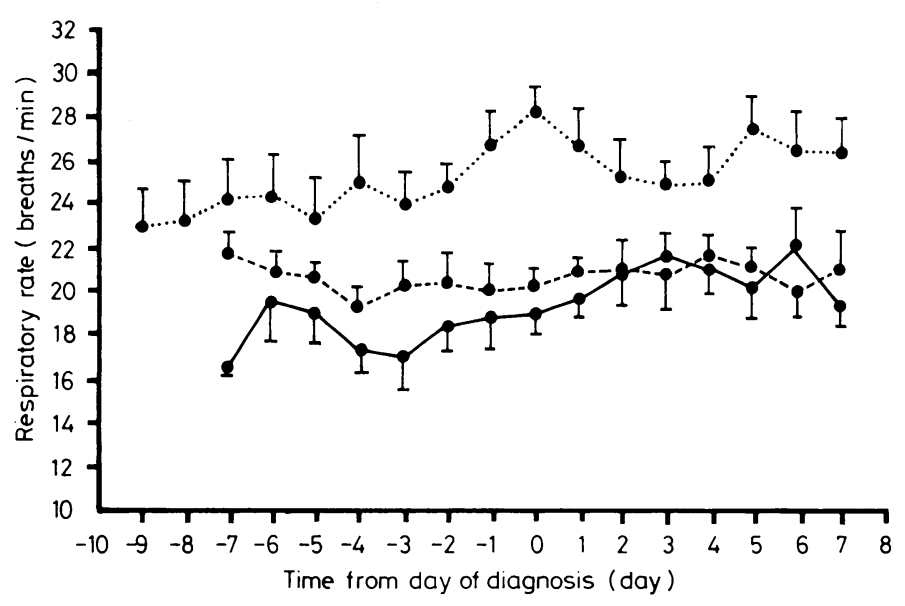

Mean ( \pm SEM) respiratory rates in 27 geriatric controls (- - - ), 12 patients with urinary tract infection (-), and 21 patients with lower respiratory tract infection $(\cdots)$. Time in days plotted either side of day of diagnosis of infection or, in controls, an arbitrary day (day 0 ).

The mean respiratory rate of the controls was fairly constant, within a narrow range overlapping that of the group with urinary tract infection: in both groups the mean on all days lay within the normal range of $16-25$ breaths/min. In contrast, the mean respiratory rate of patients with lower respiratory tract infection diverged noticeably from the control group; this divergence began three to four days before clinical recognition of the chest infection and reached a maximum on the day of diagnosis, when the mean respiratory rate was $28.2 \pm \mathrm{SD} 4.9$ breaths/min. Of the 21 patients with lower respiratory tract infection, 19 had respiratory rates above the normal range on the day of diagnosis compared with three of the controls $(p<0.002$; Fisher's exact test). Eight of the respiratory tract infections were diagnosed on the day of admission: the mean respiratory rate on that day was 29.7 breaths $/ \mathrm{min}$, with none below $26 / \mathrm{min}$. The control group, however, had a mean respiratory rate on admission of 20.8 breaths/min, with only one patient above $25 / \mathrm{min}(\mathrm{p}<0.002$; Fisher's exact test).

\section{Discussion}

It has been suggested that the routine recording of respiratory rate by nurses in hospitals should be abandoned, since indifference from clinicians leads to casual measurements that show no correlation with true respiratory rate. ${ }^{1}$ Our experience confirms the inaccuracy of such recordings: scrutiny of the nursing charts in one acute ward over three weeks showed that nurses recorded a respiratory rate between 20 and 22 breaths a minute on $62 \%$ of occasions, whereas our "accurate" measurements lay between 20 and 22 on only $23 \%$ of occasions. Accurate measurement of a raised respiratory rate, however, is reportedly a sensitive and reasonably specific marker of acute respiratory dysfunction in postoperative patients. ${ }^{6}$ That study, which arbitrarily chose a respiratory rate of 24 breaths a minute as the upper limit of normal, concluded by recommending measurement of respiratory rate as a simple, useful, inexpensive, and non-invasive screening procedure in any patient or group of patients at increased risk of respiratory dysfunction. The elderly are such a group. ${ }^{2}$

We have defined a normal respiratory rate in geriatric patients as $16-25$ breaths a minute. Most elderly patients with an acute lower respiratory tract infection develop a respiratory rate above the upper limit of this range, and the tachypnoea is often present 24-48 hours before the clinical diagnosis is made. Other acute illnesses, however, are not usually associated with raised respiratory rate. These findings confirm the teachings of experienced geriatricians who are aware of the difficulties of clinical diagnosis in the elderly. ${ }^{45}$

An accurately measured respiratory rate above 25 breaths a minute in an old person should strongly suggest the possibility of a lower respiratory tract infection even before other clinical signs are manifest.

We are grateful for the advice of Mr D Machin, department of medical statistics, University of Southampton, and to Mrs H Killham for typing the manuscript.

\section{References}

${ }^{1}$ Kory RC. The routine measurement of respiratory rate. An expensive tribute to tradition. $\mathcal{F} A M A 1957 ; \mathbf{1 6 5}: 448-50$

${ }^{2}$ Office of Population Censuses and Surveys. Studies on medical and population subjects. No 36. Morbidity statistics from general practice. London: HMSO, 1979.

${ }^{3}$ Mufson MA, Chang V, Gill V, Wood SC, Romansky MJ, Chanock RM The role of viruses, mycoplasmas and bacteria in acute pneumonia in civilian adults. Am F Epidemiol 1967;86:526-44.

${ }^{4}$ Agate J. The practice of geriatrics. London: Heinemann, 1970.

5 Wright WB. How to examine an old person. Lancet $1977 ; \mathrm{i}: 1145-6$.

6 Gravelyn TR, Weg JG. Respiratory rate as an indicator of acute respiratory dysfunction. FAMA 1980;244:1123-5.

(Accepted 26 November 1981)

MEDICINES APPROPRIATED TO THE JOINTS-The joints are usually troubled with cephalic diseases, and then are to be cured by cephalic medicines. Medicines appropriated to the joints, are called by the name Arthritical medicines. The joints, seeing they are very nervous, require medicines which are of a heating and drying nature, with a gentle binding, and withal, such as by peculiar virtue are appropriated to them, and add strength to them. It is true, most cephalics do so, yet because the joints are more remote from the centre, they require stronger medicines. For removing pains in the joints this is the method of proceeding. Pains is either taken away or eased, for the true cure is to take away the cause of the pain, sometimes the vehemency of the pain is so great that you must be forced to use Anodines (for so physicians call such medicines as ease pain) before you can meddle with the cause, and this is usually when the part pained is inflamed, for those medicines which take away the cause of pain being very hot, if there be any inflammation in the part pained, you must abstain from them till the inflammation be taken away. (Nicholas Culpeper (161654) The Complete Herbal, 1850.) 